\title{
ANTERIOR AO CONCEITO DE PESSOA: dignidade do embrião como ser humano
}

\author{
Before the concept of person: dignity of the \\ embryo as a human being
}

\section{Mario Antonio Sanches ${ }^{[a]}$, Leide da Conceição Sanches ${ }^{[b]}$}

[a] Doutor em Teologia, Mestre em Antropologia Social e Especialista em Bioética, professor de Teologia e Bioética no Bacharelado em Teologia e diretor do Programa de Pós-Graduação em Teologia da Pontifícia Universidade Católica do Paraná (PUCPR), Curitiba, PR - Brasil, email: m.sanches@pucpr.br

${ }^{[b]}$ Mestranda em Sociologia pela Universidade Federal do Paraná (UFPR), Bacharel em Direito, Licenciada em Sociologia, com especialização em Bioética pela Pontifícia Universidade Católica do Paraná (PUCPR), é professora de Sociologia e Antropologia da Saúde nas Faculdades Pequeno Príncipe, Curitiba, PR - Brasil, e-mail: leidesanches@ hotmail.com

\section{Resumo}

Em bioética vivencia-se atualmente um debate curioso ao redor do reconhecimento da dignidade do embrião. Alguns, em nome do conceito de pessoa, defendem a dignidade do embrião afirmando que todo ser humano é pessoa e merece ser tratado como tal. Outros, baseados no mesmo conceito, fazem o contrário, introduzindo uma separação entre ser humano e ser pessoa: defendem a dignidade da pessoa, mas negam que todo ser humano possa ser considerado pessoa. Para se pensar uma bioética global, é preciso construir uma reflexão que defenda a dignidade de todo ser humano, consciente de que se está lidando com uma 
diversidade de antropologias, base da diversidade cultural. Os autores deste artigo defendem, com outros autores, que o embrião é digno, não apenas como pessoa, mas como ser humano. Essa posição não nega a dualidade, mas mostra que a dignidade repousa sob o conceito de humano porque este envolve o conceito de pessoa.

Palavras-chave: Pessoa. Ser humano. Dignidade. Embrião.

\section{Abstract}

There is in Bioethics a curious debate around human embryo dignity. Some thinkers, based on the concept of person, defend embryo dignity saying that every human being is a person and is worth of being treated as such. Others, based on the same concept, mean the opposite, introducing a separation between being human and being a person: they defend the dignity of the person, but deny that every human is a person. To think a global bioethics is needed to build a thinking that defends the dignity of every human being, aware of the anthropological diversity, base of a cultural diversity. The authors of this article defend, with many others, the dignity of embryo, not just as a person, but as a human. This position does not deny a duality, but shows that the dignity relies on the concept of human itself because it involves the concept of person.

Keywords: Person. Human being. Dignity. Embryo.

\section{INTRODUÇÃO}

A pesquisa com embriões humanos tornou-se recentemente um dos temas mais debatidos na sociedade brasileira, porque levanta a questão da dignidade do embrião. A reflexão a respeito do status do embrião humano provoca um amplo debate ético e jurídico e têm suscitado os mais calorosos (não raramente contraditórios) pronunciamentos por parte de estudiosos de diferentes áreas. 
Desde o fim dos anos 70, a medicina vem, por meio de tecnologias inovadoras, reproduzindo o ser humano de maneira não usual. Por mais que essas chamadas técnicas de reprodução assistida tenham sido aperfeiçoadas, inúmeros embriões humanos continuam sendo criopreservados. Inicialmente isso foi feito com o propósito de melhorar os resultados dos serviços prestados pelas clínicas de reprodução assistida, mas, na sequência, muitos embriões acabaram sendo inseridos numa nova, confusa e controversa categoria classificada de "embriões excedentes" ou "embriões supranumerários". Não mais desejados pelas partes interessadas no processo da reprodução, esses embriões fazem parte do cenário das Clínicas de Reprodução sem um propósito claro e sem uma perspectiva definida.

Estamos assim diante de um dos conflitos éticos mais difíceis de ser adequadamente solucionados na atualidade: o que fazer com esses embriões? Olhando para o passado - para os embriões já congelados - não se vê resposta satisfatória, mas olhando para o futuro, é necessário assumir um compromisso de parar de congelar embriões. Por isso gostaríamos de nos colocar ao lado de todos aqueles que insistem que precisamos regulamentar a reprodução assistida no Brasil para, entre outras coisas, inibir o congelamento indefinido de embriões.

Tendo esse cenário em mente e com o objetivo de somar esforços para uma solução adequada às questões éticas suscitadas pela manipulação de embriões humanos, gostaríamos de indicar que a dificuldade para defender a dignidade de um embrião passa, dentre muitas questões, pela assertiva teórica e prática no reconhecimento da dignidade de cada ser humano: o ser humano é digno pelo simples fato de existir, ou sua dignidade depende de ser reconhecido social e juridicamente?

\section{Os termos desse dualismo}

No âmbito da bioética, esse dualismo entre existir e ser aceito tem se explicitado nas diferenças entre os conceitos de 'pessoa' e de 'humano'. Num outro trabalho (SANCHES, 2004, p. 79-94) abordamos mais amplamente o assunto, analisando as diferentes posições: a) uma que assume que todo ser humano é pessoa e toda pessoa é humana; b) a outra posição defende que nem todo humano é pessoa e nem toda pessoa é humana. Ess última tendência define o 'ser humano' como todo ser pertencente à espécie homo sapiens e 'pessoa' 
como todo indivíduo que tem "consciência de si, auto-controle, senso de futuro e passado, capacidade de relacionar-se com os outros, preocupação com os outros, comunicação e curiosidade" (SINGER, 1998, p. 96). Nessa perspectiva, o embrião humano, com toda certeza é identificado como ser humano, pois ele pertence à espécie homo sapiens, mas ainda não pode ser chamado de pessoa, pois não tem consciência de si nem capacidade de relacionar-se com os outros.

Essa tendência, bastante presente na literatura em bioética, afirma que $o$ embrião, o feto, a criança com profundas deficiências e o próprio bebê recémnascido são, todos, membros inquestionáveis da espécie homo sapiens, mas nenhum deles é autoconsciente, tem senso de futuro ou capacidade de se relacionar com os outros. Portanto, a escolha entre essas duas tendências pode fazer uma diferença enorme no que diz respeito à afirmação da dignidade do embrião humano.

Gostaríamos de deixar claro que podemos dialogar com esse dualismo, e até mesmo aceitá-lo, por dois motivos: por um lado, ele é fruto da nossa própria cultura ocidental e só pode ser compreendido a partir dela; por outro lado, ele não se opõe à plena dignidade do ser humano, mas o confirma. Ou seja, mesmo concordando com o dualismo - entre 'ser humano' e 'pessoa' -, não há razões para migrar a afirmação da dignidade unicamente para o conceito de pessoa, independente do conceito de humano, como afirma Peter Singer (1998, p. 104).

O termo 'pessoa' surgiu na Grécia antiga, berço da cultura ocidental, significando a máscara de atores, expressando a distinção entre a identidade do ator e o personagem que ele representa. Daí decorre que pessoa passa a ter o papel social, lugar do indivíduo em sua sociedade. Surge, assim, a possibilidade teórica de pensar numa distinção entre o que o indivíduo é (sua essência) e o modo como ele se manifesta (sua expressão). Toda essa reflexão sobre pessoa se aprofunda na teologia cristã, que também marca profundamente o pensamento da cultura ocidental.

O cristianismo nascente se coloca diante da figura de Jesus de Nazaré, compreendido para os cristãos como o homem-Deus, que com sua natureza humana e divina se torna parte da história humana. Jesus, o homem-Deus, é uma pessoa com duas naturezas: a humana e a divina, compreendendo que "natureza é o que uma pessoa é essencialmente, e pessoa (prosopon) é como ela aparece" (BRAATEN, 1990, p. 490). Assim se consolida o dualismo entre os dois termos, pois da reflexão sobre a pessoa humana-divina de Jesus Cristo decorre também que cada indivíduo é uma pessoa com uma natureza humana. Na perspectiva da tradição cristã, 'ser pessoa' e 'ser humano' são 
duas realidades intercambiáveis, inseparáveis, que formam a base da dignidade humana: compartilhar com o Filho de Deus a mesma natureza humana, e ser chamado por Deus a um relacionamento pessoal. Nessas duas condições o cristianismo fundamenta a dignidade ímpar de cada ser humano, em qualquer fazer de seu desenvolvimento. Essa perspectiva é a base do pensamento ocidental que defende a expressão máxima da dignidade humana.

A bioética, que deve dialogar com a diversidade moral e cultural global, não apenas com a diversidade existente dentro da sociedade ocidental, deve reconhecer que não pode reduzir o conceito de humano somente à antropologia ocidental. Por isso, se queremos uma visão antropológica funcional para um discurso que se pretenda universal, essa deve surgir da tensão e do debate entre as diferentes antropologias das diferentes sociedades. A partir da antropologia social, afirmar-se-ia, com certa facilidade, que essa é uma missão difícil. Isso porque a diversidade cultural é um fato e o conceito de humano, como elemento central da cultura, está no cerne dessa diversidade.

A bioética deve assumir posições que apontem algumas tendências gerais no tocante à dignidade humana, para depois dialogar com os elementos culturais locais. A questão deixa de ser a busca de uma visão antropológica que seja consenso universal para a busca do reconhecimento da dignidade humana de maneira universal (KUNG, 1993, p. 127).

\section{Quem é digno: a pessoa ou o ser humano?}

A questão antropológica, analisada acima, identifica o dualismo: ser membro da espécie humana e ser pessoa humana. Ao invés de negar o dualismo, vamos aceitá-lo e analisar sua natureza. Que tipo de dualismo é esse? Entendemos que não se trata de um dualismo ontológico, tendo em vista que a distinção entre ser membro da espécie humana e ser pessoa não se funda na existência de substâncias distintas para cada realidade. Sugerimos, portanto, que a complexidade da existência possa ser compreendida como um 'dualismo histórico' e uma ‘tensão existencial', pois o humano enquanto ser é apenas um momento histórico diferente do humano enquanto pessoa: dualidade histórica.

Compreender o dualismo como histórico é importante porque possibilita o diálogo com a diversidade moral e cultural. É basicamente dualismo entre existir como ser humano e existir como membro aceito de uma determinada 
sociedade, ou grupo. É dualismo histórico, porque marca momentos diferentes da história do indivíduo. Mas não é dualismo ontológico, porque o mesmo ser que existe passa a ser aceito. Existir e ser aceito são elementos decorrentes um do outro, não elementos distintos.

A dignidade não é uma afirmação científica, mas social. Concordamos com Peter Singer (1998, p. 30) quanto à dignidade ser, como a igualdade, "um princípio ético básico, e não uma assertiva factual". Afirmar a dignidade humana é afirmar o valor que a vida humana ocupa no sentido da existência do próprio ser humano. Isso pode parecer óbvio demais, mas é exatamente assim: o ser humano, na busca de sentido para a própria existência, atribui à vida humana uma dignidade fundamental.

$\mathrm{O}$ fato do ser humano atribuir à vida humana uma dignidade especial pode parecer autoelogio, autocondescendência. Diríamos que se o reconhecimento da dignidade humana tiver um conteúdo subjetivo e sujeito à apreciação individual, então sim, torna-se um exercício de autopiedade. Nesse caso o indivíduo avaliaria sua própria dignidade e a dos outros e não raramente se colocaria como modelo de humano. Assim, valorizaria sua dignidade, a de seu grupo, a de sua classe, a de sua cultura, como digna de ser defendida, e a dos outros somente na medida em que se parecer com a sua. Se assim fosse, não teria ética, mas etnocentrismo.

Defender a dignidade humana na perspectiva da ética situa-se na direção oposta ao etnocentrismo. Por isso entendemos que é necessário abordar a problemática da dignidade humana na sua extensão, pois se a dignidade da vida humana faz sentido - e não é mero exercício de autopiedade - ela deve ser afirmada em sua máxima extensão: a vida humana de todos os humanos é digna. Isso deixa de ser autocondescendência e se torna um programa arrojado e exigente, teórico e prático, e o indivíduo passará a respeitar a vida humana e não poderá mais dispor dela a seu bel-prazer.

Ao reconhecer que a realidade humana se situa entre dualismos, não devemos estabelecer uma postura bioética dual: a dignidade humana perpassa toda a história do ser humano, e do humano inteiro, por mais que uma ou outra cultura venha fragmentar sua compreensão de humano, de mundo. Desse modo, apresenta-se, a seguir, o desdobramento da afirmação da dignidade humana:

a) O dualismo histórico, frente às tensões entre natureza e cultura, conduz o humano à tensão entre existir e ser aceito: disso decorre 
que existir como membro da espécie humana corresponde à máxima extensão factual da dignidade humana;

b) O dualismo histórico, diante das tensões entre o particular e o universal, conduz o humano à tensão entre ser cidadão de sua pátria ou ser cidadão do mundo: donde decorre que ser cidadão do mundo corresponde à máxima extensão relacional da dignidade humana. Vejamos melhor essas duas afirmações.

\section{A dignidade na máxima extensão factual}

Evocar a inter-relação entre natureza e cultura é evidenciar como o ser humano se faz gente numa determinada cultura. Até mesmo aspectos fisiológicos do ser humano são influenciados pelas práticas culturais (MELLO, 1983, p. 55) e surgem como marcas das pessoas formadas em seu contexto sociocultural específico. O estudo da relação natureza-cultura aponta para um elemento comum a todos os humanos: a realidade cultural (SANCHES, 2004, p. 61-68).

Desse modo, o dualismo histórico é bem destacado: há um existir factual do humano e há o seu reconhecimento cultural como pertença a uma determinada sociedade. A cultura marca profundamente o ser humano, de modo que o ser humano é um ser situado numa cultura. Mas o ser humano tem em seu início uma existência factual, não cultural, e aí o dualismo se estabelece como histórico. Um embrião fecundado, já humano em sua existência factual, não é ainda um ser humano aceito socialmente por uma determinada cultura. Seu futuro cultural é indefinido. Poderá vir a ser um brasileiro, um esquimó, um banto, um terena, um japonês... Se por um lado a pessoa humana é essencialmente um ser cultural, pois não se pode separar um humano adulto de suas marcas culturais, por outro lado isso pressupõe sua existência factual, cronologicamente anterior à sua cultura.

A divisão do pensamento ocidental entre 'ser membro da espécie humana' e 'pessoa', compreendida como expressão desse dualismo, possibilita a identificação mais ampla do 'ser da espécie humana' como existência factual, e ser 'pessoa' como ser socialmente aceito. Assim, do mesmo modo que ser socialmente aceito é precedido cronologicamente de sua existência factual, assim também o ser 'pessoa-humana' decorre do 'ser-da-espécie-humana'. Tratase de uma dualidade histórica, não ontológica, não essencial. 
Reconhecer essa dualidade histórica significa valorizar o processo que flui de um a outro momento, ou seja, está se destacando que esse processo de fazer-se pessoa no mundo pressupõe a realidade inalienável do ser humano como membro da espécie. Além disso, destaca-se também que esse ser assume sua expressão real na pessoa quando essa se manifesta, e que, portanto, não é possível separar o humano enquanto pessoa do humano, enquanto ser, que é a sua base. Um feto ainda não aceito como plenamente pessoa - em todas as culturas - já é um ser humano, e se tornará plenamente pessoa exatamente porque é humano.

Em termos ocidentais pode-se dizer que o termo pessoa é que diferencia o ser. O termo pessoa não é acidental no ser, mas o modo como o ser se manifesta no mundo. Nesse dualismo toda pessoa humana é ser-da-espéciehumana, mas nem todo ser humano é universalmente compreendido como plenamente pessoa. Isso porque ocorre que os seres intrauterinos ainda não se expressaram totalmente e, portanto, detêm a realidade de ser humano, não sua expressão plena como pessoa.

No entanto, ao conceituar o ser humano como uma dualidade histórica, composta de um ser (natureza/substância ou simplesmente existente) e sua manifestação (pessoa, cidadão ou simplesmente membro aceito de um grupo), pode-se concluir uma unidade básica entre todos os humanos: que todos os seres humanos são iguais no ser e são diferenciados enquanto manifestação histórica concreta.

A dignidade e o valor do ser humano repousam em cada um desses aspectos, manifestados nesse dualismo histórico. A dignidade decorre do fato dele existir e também, posteriormente a isso, de ser aceito. No debate se os "embriões supranumerários" ou o feto no útero materno merecem ser tratados com a dignidade reservada a um ser humano integral, alegando que esses ainda não são pessoas, cabe responder que o conceito de pessoa não está associado ao âmbito do ser e que, anterior (cronologicamente) ao conceito de pessoa, há o conceito de ser humano.

Deve-se reconhecer a possibilidade de alguém construir seu sentido da vida, baseado no não reconhecimento da dignidade de todos os humanos. Mas quando se pretende uma bioética universal, cumpre estar atento ao fato de que a humanidade tem percorrido a tendência de maximizar a dignidade humana. O infanticídio, o extermínio de pessoas doentes, deficientes ou em coma, o extermínio de idosos, mesmo quando são práticas aceitas numa determinada cultura, têm sido condenadas veementemente em fóruns internacionais. $\mathrm{O}$ direito 
do escravocrata, pessoa socialmente valorizada, sobre a vida do escravo (nãopessoa), praticado na antiga Roma, e no Brasil até o fim do século XIX, é hoje radicalmente refutado.

Por outro lado, fundar a dignidade humana na 'pessoa' como autoconsciente, ou no cidadão enquanto socialmente aceito, seria o mesmo que fundar a dignidade humana numa posição passível de sofrer um amplo escalonamento. Além disso, estaríamos incorrendo numa ideologia de só reconhecer a dignidade dos humanos parecidos conosco. Pessoas com problemas de saúde, ou submetidos a tratamentos poderão ter seu estado de consciência alterado. Pensadores da pós-modernidade poderiam questionar: será que existe autoconsciência ou interconsciência, visto que o indivíduo é envolvido por um processo de "produção de subjetividade"? (GUATARI, 1999, p. 26).

Concluindo, é necessário defender a máxima extensão factual da dignidade humana que reside no existir como membro da espécie humana, ou seja, negando a dignidade a um ser da espécie humana, nega-se a dignidade a um ser humano, integralmente.

\section{A dignidade na máxima extensão relacional}

Num outro trabalho (SANCHES, 2004, p. 71) identificamos a dificuldade de conciliar o universal e o particular, isso porque, quando se afirma o universal, corre-se o risco de oprimir o particular; quando se afirma o particular, cai-se no risco do relativismo. No entanto, na perspectiva antropológica do dualismo histórico, percebemos a tendência ao reconhecimento de elementos universais para afirmar a dignidade humana.

Romper o dualismo entre existir e ser aceito, ou entre 'ser humano' e ter sua dignidade reconhecida, tem sido uma tarefa espinhosa para muitas pessoas. A reflexão latino-americana do movimento da libertação indica os fatores ideológicos que têm levado um bom número de seres humanos à exclusão social, e têm deflagrado uma luta para a derrubada das barreiras sociais.

A exploração econômica de um ser humano por outro, por um sistema econômico ou mesmo por um governo, não raro está sustentada num esquema ideológico em que a dignidade do explorado é teórica e praticamente negada ou diminuída. Uma pessoa humana que alardeia sua própria dignidade se sentiria constrangida em explorar outro ser humano de dignidade igual. Por isso, os 
esquemas ideológicos de dominação vão se sofisticando para que a dignidade do explorado não apareça, e o explorador possa continuar alardeando a sua dignidade.

A história da América Latina é a história desse caminho, em que a grande maioria de seus filhos tenta afirmar que existe e tem dignidade. Os europeus, ao iniciarem o contato com os nativos latino-americanos, iniciam também a história da negação da identidade desses. Os nativos, os assim chamados 'índios', foram violentados em sua cultura, em suas pessoas e submetidos à escravidão. Por trás da dominação pairava o debate da época: será que os nativos têm alma? “Os índios são homens?” (DUSSEL, 1977, p. 9). $\mathrm{O}$ que correspondia a dizer que os nativos não eram bem humanos, mas "homúnculos nos quais mal encontrarás vestígios de humanidade" (SEPULVEDA, 1992, p. 523).

Diminuindo a dignidade dos 'índios', justificava-se a dominação desses pelos espanhóis e portugueses. Era até visto como um privilégio para os nativos serem colonizados por tão ilustres e dignos senhores, "excelentes em todo gênero de virtudes" (SEPULVEDA, 1992, p. 534). O esquema de justificação da dominação e escravidão se repetiu com os povos africanos, com a invenção do conceito de raça (BANTON, 1977, p. 12) e o desenvolvimento das teorias 'científicas' do racismo (SCHWARCZ, 1987, p. 23). No Brasil, essas teorias culminaram na chamada tese do branqueamento (SANCHES, 1997, p. 16). Do passado ao presente, o esquema ideológico é sempre o mesmo, a dignidade do dominado é diminuída, aviltada, para que o dominador possa se sentir bem, pois sendo uma pessoa 'virtuosa' teria dificuldade em explorar um ser humano igualmente digno.

Movimentos recentes, como o da Unesco, em 1956, condenou explicitamente "a manipulação ideológica do conceito (de raça), fazendo sempre a distinção entre raça, como fator biológico, e os mitos raciais produzidos pelo racismo" (SEYFERTH, 1995, p. 176). Assim, muitos documentos produzidos pela ONU, desde a carta dos Direitos Humanos, vão sendo entendidos como defensores da dignidade de todos os humanos e do humano todo.

Frente a tudo isso, afirmamos que é necessário reconhecermos que quando se fala que os embriões fecundados em laboratório, os fetos e os recémnascidos são humanos, mas não pessoas, e por isso não gozam da mesma dignidade, ou de dignidade alguma, está se reproduzindo o velho esquema ideológico de diminuir ou negar a dignidade de um grupo de seres humanos, para dele se apossar e dele dispor como bem aprouver. 
Por mais que queiramos fundamentar em teorias antropológicas a superioridade moral dos humanos-pessoas contra os humanos-ainda-nãopessoas, entendemos que isso não se justifica e esconde uma cruel ideologia, por várias razões:

a) essa divisão entre humano e pessoa ocorre na compreensão ocidental de ser humano, que não pode ser imposta a outras culturas;

b) dentro da própria cultura ocidental, mesmo aceitando a divisão entre 'humano' e 'pessoa', muitos, no qual nos incluímos, reconhecem a dignidade do 'humano' que inclui a 'pessoa' e não apenas da 'pessoa' excluindo o 'humano';

c) essa teoria não é neutra, mas traz consequências desastrosas para boa parcela dos seres humanos, que são excluídos da dignidade;

d) há pessoas e grupos sociais que tiram vantagens econômicas dessa teoria, mostrando que ela é uma ideologia para esconder uma prática;

e) práticas terríveis podem ser acobertadas pela negação da dignidade a todo o ser humano, tais como: a venda de peles de fetos e dos próprios fetos para indústria farmacêutica e cosmética; a destruição de uma infinidade de embriões fecundados em laboratórios; experiências genéticas com embriões fecundados (SMITH, 2000, p. 228), entre outras.

Desse modo, é necessário denunciar como ideologia excludente toda e qualquer teoria que fundamente a dignidade humana apenas na proporção em que determinado ser humano possua uma relação próxima ao grupo ao qual pertence. A perspectiva ética da dignidade humana deve levar essa relação à máxima extensão possível. São dignos não apenas os que pertencem ao nosso grupo, mas todos; não apenas os que pertencem ao nosso grupo familiar, mas também o estranho; não apenas os que pertencem à nossa classe social, mas também os de outra classe social; não apenas os que pertencem à nossa religião, mas também os de outras crenças; não apenas os que possuem 'autoconsciência' como nós, mas também os que ainda não são dotados de consciência; não apenas os que pertencem à nossa pátria, mas também os estrangeiros. Isso significa exatamente reconhecer e defender a dignidade humana de todos os membros da espécie Homo sapiens. Deste modo, a máxima 
extensão relacional da dignidade humana está em reconhecer a dignidade humana plena de um embrião estrangeiro.

\section{A dignidade humana e dos outros animais}

As pessoas que defendem a dignidade de todos os humanos, como o fazemos e explicitamos acima, seriam claramente taxadas por autores como Peter Singer de 'especistas', ou seja, alguém que coloca a própria espécie acima das outras espécies (SINGER, 1998, p. 98). Não há como negar que a posição de julgarmos nossa espécie superior às outras decorre do fato de que a ela pertencemos. Como a comunicação entre as espécies é precária - uma interação para a convivência pacífica, repetições mais ou menos mecânicas, sintonia afetiva, comunicação intuitiva - fica difícil saber o que as outras espécies pensam de nós. Se alguém defender que somos exatamente nós, os humanos, que devemos estabelecer os valores, já está afirmando que temos o poder para isso e, portanto, somos uma espécie ímpar. Como não é possível convocar um congresso com representantes de diferentes espécies animais para estabelecer uma teoria ética universal, somos nós que temos que tentar fazê-la. Claro que isso não justifica um antropocentrismo arrogante.

O ser humano constrói o sentido de sua existência a partir de sua subjetividade própria, na relação intersubjetiva com os outros e com o mundo. A ética não pode negar isso, mas deve convidar o ser humano a se abrir para o reconhecimento da dignidade dos outros seres da mesma espécie, dos membros de outras espécies animais, até atingir o reconhecimento da dignidade do cosmo como um todo e em cada parte.

Mas, se é possível criar um novo termo discriminatório, 'especista', para enquadrar quem atribui maior dignidade aos membros de sua espécie, é possível também criar outro neologismo "personacista", igualmente pejorativo, para enquadrar quem atribui maior dignidade às pessoas. Um "especista" atribui maior dignidade aos humanos porque ele mesmo é humano. Um "personacista" atribui maior dignidade à pessoa por-que ele mesmo se considera uma pessoa. Assim, criticando o "especismo", Singer pode ter caído numa posição ainda mais discriminatória, por vários motivos: 
a) por ter lançado mão de um termo de sua própria cultura, o termo 'pessoa', para dividir todos os animais, incluindo os humanos, em duas categorias: os que são pessoas e os que não são pessoas, e desse modo ele se tornou, antes de qualquer coisa, etnocêntrico;

b) porque ele repete o vício que queria denunciar nos que ele chama de "especistas", que é o de se incluir na categoria privilegiada;

c) porque ele estaria excluindo da mesma dignidade seres que, em questão de tempo, seriam igualmente pessoas e que poderiam, inclusive, suplantá-lo em capacidade de autocomunicação e outras características do ser pessoal.

Desse modo, entendemos como absolutamente equivocada a seguinte afirmação: "Os fetos, os bebês, os deficientes mentais e aqueles que se encontram em coma, sem possibilidade de recuperação, são humanos, mas não pessoas. São membros da espécie humana, mas não desfrutam, por si mesmos, uma posição na comunidade moral secular" (ENGELHARDT, 1998, p. 174). Em nome dessa 'comunidade moral secular' continua-se afirmando: “assim, parece que o fato de, digamos, matar um chimpanzé, é pior do que o de matarmos um ser humano que, devido a uma deficiência mental congênita, não é e jamais será uma pessoa" (SINGER, 1998, p. 127).

Considerar necessário, para reconhecer em alguém um valor moral, o fato desse alguém ser capaz de autoconsciência, ou de defender por si só seu valor, é uma posição muito perigosa e pode abrir brechas para incalculáveis aberrações. Um governo ou a elite dominante poderiam dizer, por exemplo, que boa parte da população 'não tem consciência' das coisas e colocar-se-iam no direito de agir em nome dessa, tomar decisões que a afetam, sem a sua participação. Estaríamos novamente à mercê de todo o processo de manipulação ideológica de exclusão.

É necessário afirmar que um ser humano tem valor moral, independente de sua capacidade de fazê-lo valer, ou ter consciência de sua dignidade, isto sem negar a importância da autoconsciência e liberdade, como elementos fundamentais da pessoa. Deve-se afirmar uma coisa sem negar a outra de maneira objetiva, de modo que alguns poderão continuar não reconhecendo esse valor, mas não continuar se afirmando eticamente corretos ao fazer isso, nem tentando apresentar isso como universalmente válido. 
Além disso, para defender a dignidade da vida de todos os animais são necessários muitos outros argumentos. Não basta apenas insistir que alguns animais de outras espécies, na realidade bem poucos, quando bem treinados pelos humanos, ou superdotados, ou bem domesticados, também têm certa autoconsciência e são, portanto, também pessoas. Se alguém for capaz de sacrificar uma criança de um mês, por uma justificativa racional de que essa não é ainda uma pessoa, é improvável que essa atitude possa desenvolver maior sensibilidade e respeito para com os outros animais.

Nós concordamos com Barbour (1990, p. 191), quando ele afirma que se as pesquisas, em décadas recentes, têm encontrado em alguns pontos mais similaridades com outras formas de vida do que eram previamente suspeitadas, "estas descobertas deveriam levar-nos a um maior respeito por aquelas formas, mas não a negar a dignidade humana. Em outros pontos, a ciência contemporânea oferece amplo testemunho da unicidade da humanidade entre as criaturas do planeta Terra".

\section{CONCLUSÃO}

A distinção entre os termos "humano" e "pessoa" passa a ser aceita pela bioética; no entanto, em bioética, não há consenso se a atribuição de dignidade se refere ao humano ou à pessoa. Alguns entendem que para a ética secular, "a pessoa e não os humanos são especiais" (ENGELHARDT, 1998, p. 169). Para esses, o que é importante não é o fato de pertencermos à espécie Homo sapiens, mas o fato de que somos pessoas.

Outros, dentre os quais nos incluímos, aceitam a distinção entre os termos, mas sugerem que a atribuição de dignidade se refere ao termo "humano", mais amplo: "Em resumo, se ousamos propor este condensado, o embrião é digno, não como pessoa, mas como ser humano" (LEPARGNEUR, 1996, p. 102). Essa posição não nega a dualidade, mas mostra que a dignidade repousa sob o conceito de humano porque esse envolve o conceito de pessoa.

De qualquer modo, para se falar de dignidade humana, no contexto da bioética, é necessário estarmos atentos à linguagem usada e à distinção entre os termos "humano" e "pessoa". Defendemos ao longo deste trabalho que é necessário defender a dignidade do humano em si em todos os momentos de sua vida, como afirma João Paulo II: “A vida humana é sagrada e inviolável 
em cada momento de sua existência, inclusive na fase inicial que precede o nascimento" (JOÃO PAULO II, 1995).

Precisamos também estar atentos e defender a dignidade de cada ser vivo, segundo sua própria espécie. Lançar mãos do conceito de pessoa para defender a dignidade dos animais capazes de autoconsciência é assumir uma atitude extremamente ingênua, pois incluiria pouquíssimas espécies nesta categoria e lançaria $98 \%$ das espécies de seres vivos do planeta no rol dos "não-pessoa", dos que têm dignidade nenhuma, por serem não sensientes.

Afirmar a dignidade de cada ser humano é um primeiro passo para afirmarmos a dignidade de cada ser vivo do planeta, não com base na sua dinâmica interna, mas simplesmente por existirem. É a simples existência de ser, sua realidade factual, que nos impõe seu valor. Numa perspectiva cristã diríamos: são dignos porque são criaturas de um ser Absoluto que ama e conhece cada criatura.

\section{REFERÊNCIAS}

BANTON, M. A idéia de raça. São Paulo: Edições 70, 1977.

BARBOUR, I. G. Religion in an age of science. London: SCM Press, 1990.

BRAATEN, C. E. A pessoa de Jesus Cristo. In: BRAATEN, C. E.; JENSON, R. W. (Ed.). Dogmática cristã. São Leopoldo, RS: Sinodal, 1990. v. 1, p. 462.

DUSSEL, E. Filosofia da libertação na América Latina. São Paulo: Loyola, 1977.

ENGELHARDT Jr., H. T. Fundamentos da bioética. São Paulo: Loyola, 1998.

GUATARI, F.; ROLNIK, S. Micropolítica: cartografia do desejo. 5. ed. Petrópolis: Vozes, 1999.

JOÃO PAULO II. Evangelium vitae. 2. ed. São Paulo: Paulinas, 1995.

KÜNG, H. Projeto de ética mundial: uma moral ecumênica em vista da sobrevivência humana. São Paulo: Paulinas, 1993.

LEPARGNEUR, H. Bioética e o conceito de pessoa: esclarecimentos. In: PESSINI, L.; BARCHIFONTAINE, C. P. Fundamentos da bioética. São Paulo: Paulus, 1996. p. 89-107. 
MELLO, L. G. Antropologia cultural: iniciação, teoria e temas. Petrópolis: Vozes, 1983. SANCHES, M. A. Bioética, ciência e transcendência. São Paulo: Loyola, 2004.

O negro em Curitiba: a invisibilidade cultural do visível. 1997. Dissertação (Mestrado Antropologia Social) - Universidade Federal do Paraná, Curitiba, 1997.

SCHWARCZ, L. M. Retrato em preto e branco. São Paulo: Companhia das Letras, 1987.

SEPÚLVEDA, J. G. As justas causas de guerra contra os índios (1547). In: SUESS. P. (Org.). A conquista espiritual da América Espanhola: 200 documentos - século XVI. Petrópolis: Vozes, 1992. p. 531-538.

SEYFERTH, G. A antropologia e a teoria do branqueamento da raça no Brasil: a tese de João Batista de Lacerda. Revista do Museu Paulista, São Paulo, v. 30, p.81-98, 1995.

SINGER, P. Ética prática. São Paulo: Martins Fontes, 1998.

SMITH, J. W. Culture of death: the assault on medical ethics in America. San Francisco, California: Encounters Books, 2000.

Recebido: 21/09/2009

Received: 09/21/2009

Aprovado: 30/10/2009

Approved: 10/30/2009 